\title{
THE AUTHENTICITY OF THE DYNAMIC- AGOGIC ELEMENTS IN BEETHOVEN'S LANGUAGE PERCEIVED THROUGH THE PERSPECTIVE OF THE PIANO AND VIOLIN SONATAS
}

\author{
Itigan Mihaela*, Drăgulin Stela \\ Transilvania University, Braşov, 500036, Romania. \\ *e-mail address: mitigan@yahoo.com
}

\begin{abstract}
In the history of classical music from the end of the 18th century and the beginning of the 19th century, Beethoven stands out as the creator of an authentic and prolific musical language which opens new aesthetic and stylistic horizons, particularly to instrumental music. In his monumental work of this type, the ten duets composed in the form of sonatas for piano and violin have a special place, enriching thus the specialised literature. From the very first opus, they resemble the chamber pieces that reflect a new technical-interpretative approach of the instrumental ensemble. In the composer's vision, the pairs of instruments are treated as soloists to create a partnership between them based on the expressivity and tone colour of each one of them. The musical language used reveals a Beethovenian perspective that is extreme in terms of dynamics, generous in terms of agogic accents and rich from the point of view of its expression. The performance of these pieces in this way provoked numerous critical reactions among conservative musicians. The suspicions linked to the authenticity of these stylistic features are fueled by their graphic representation, which some editions mistakenly present, thus generating confusion among performers. This article aims to present an overview of the graphic analysis of the ten pieces for piano and violin, by comparing several editions, in order to confirm the existence of some musical elements typical of Beethoven's style and to mark the significant differences through which these stylistic features can be ignored or misinterpreted. Special attention will be given to the dynamic elements, their variety and innovative character being among the specific language features that provide substance to the musical discourse and render it unique. The analysis will continue with an in-depth research of the sonatas from the agogic perspective of the musical text, placing its graphic representation in the context of artistic performance.
\end{abstract}

Keywords: Art \& Music, sonatas, Beethoven's language, dynamic, agogic

\section{Introduction}

Any instrumental work which is representative of cult music employs a specific language from which the author, using their compositional virtuosity, develops the expressiveness, the sense and the uniqueness of the musical discourse. A qualitatively weak discourse interpretation, from the viewpoint of the expressive particularities the composer lends to the musical piece, can be the consequence of its superficial approach from a graphic point of view. The studied edition therefore does not represent one of the most adequate ones.

More often than not, the multiple publication of the same text has resulted in several versions, where subjective editorial notes have altered, or even deformed, the artistic message of certain musical fragments. Most influences occur in the area of 
dynamics, musical nuances being easily manipulated by the editors, under the pretext of their questionable authenticity, in relationship with the style particularities or the expressive possibilities of the instruments. The choice of a reliable edition, which would faithfully reproduce the first edition or even the manuscript, if it exists, ensures a veritable representation of the respective work's particularities. Moreover, the approach itself shows respect to the composer's intentions, as well as a responsible attitude towards the musical act.

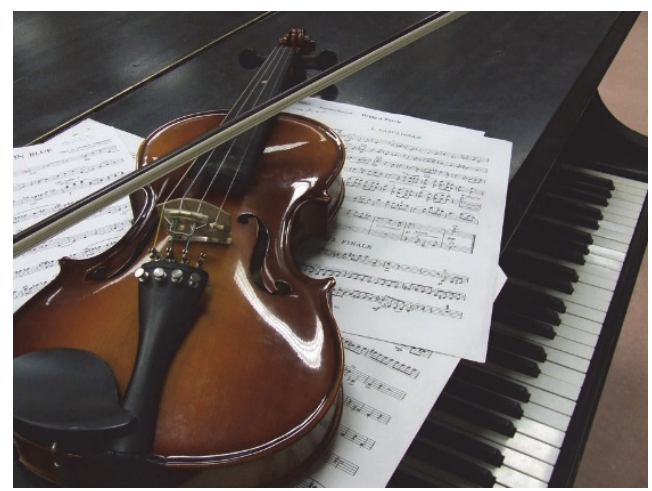

Confirming the authenticity of the stylistic and interpretative details that are representative for the studied pieces is an important first step in the process of instrumental perfecting of the artistic repertoire. This is why the graphic analysis of the text should be, as violinist Max Rostal stated, every interpreter's "primary and essential concern" [1].

Starting from this prerequisite, the present article aims to highlight the importance that the graphic approach of a repertoire has in any performance, from the perspective of several editions. Using comparison as an analytic method, it emphasizes certain dynamicagogic details present in the first editions of the ten Beethovenian sonatas written for piano and violin. These details are partly modified or even totally ignored in the pages of certain subsequent editions. The inherent ambiguity generated by this situation may lead to an erroneous interpretative conception of the musical context in which all these details appear. Consequently, the graphic study of a more authentic edition is necessary, if not even compulsory in this case.

\section{Beethoven's Sonatas for Piano and Violin}

The sonatas for piano and violin are emblematic pieces of the genre through the force and expressiveness of their musical fragments, sustained in a perfect balance by the discourse of the two lead instruments. Adding to the artistic diversity and complexity, the technical difficulties give weight to the pieces, turning them into a real technical-interpretative challenge, even for experienced instrumentalists. Even from his first opus, Beethoven conveys his strong personality onto his pieces, providing the sonatas with ample and daring lines, shaped under a form which fights to break the humble classical barriers of the genre. Significantly exploiting the possibilities of the two instruments, especially the expressive ones, Beethoven radically changes the perception of chamber music, from accessible music, played by amateur instrumentalists in exclusive circles, to music worthy to be played in concert halls. Moreover, between the lead instruments he creates a partnership based on the expressiveness, timbre and colour representative of each of them.

The sonatas are known to the general public under various editions, some of them containing, in certain bars, annotations which have nothing in common with the original text. All these notes originate in the editor's subjectivity who, passing the musical content through his own filter, may present it as somewhat distorted, influencing even radically, in certain cases, the instrumentalist's vision. To avoid any confusion, it would be advisable that these editorial alterations appear between parentheses or as footnotes in the score, as alternative suggestions, or details. Marking them in a way that makes them visible in the context offers the instrumentalists a clear image regarding their origin.

The most popular and most widely used editions are Peters, Breitkopf and Hartel, as well as the German edition G. Henle. The support for the present article is the Peters edition, coordinated by the German violinist and conductor Walther Davisson. Historically, it is worth mentioning that the publication of this edition coincides with the 
start of the 1800's and was made possible by the institution entitled "Bureau de Musique" from Leipzig, under the supervision of the Viennese composer Franz Anton Hoffmeister and organist Ambrosius Kuhnel. Valuable compositions by Bach, Mozart, Haydn and of course, Beethoven, were also published here. For an objective examination, the article bases its analysis on the research of the ten sonatas published by G. Henle Verlag, a Munich based publishing house, in the south-east of Germany, specialized in Urtext editions, as well as that of the first edition, namely: Artaria in the case of Sonatas op.12, edition coordinated by Tranquillo Mollo for op. 23, 24 , and the original edition published by the "Bureau d'Arts et d'Industrie" in Vienna for the three Sonatas op.30. The last two sonatas, the monumental Kreutzer and the lyrical opus 96 were first published by Simrock in German and by Birchall in English. Even though they are among the most respectable publishing houses in the field, differences appear in their publications, an observation which is confirmed by the comparison with the first edition. The differences are, in the first place, of a dynamic nature, which, paradoxically, can be seen in the existing manuscripts, minutely detailed by Beethoven.

\subsection{Dynamic Elements of Beethoven's Sonatas for Piano and Violin}

Dynamics, a dominant element of the musical language, is what alters the variation of sound intensity. For Beethoven, the dynamic was an important side of the musical language and he dedicated his entire life to exploiting all its aspects and succeeded in capturing, as Angus Watson noted, all its expressive and dramatic power. "Beethoven had experienced the expressive and dramatic effectiveness of varied dynamics, and this remained for him a vital concern throughout his life."[3]

Being aware of the crucial role the sound intensity plays in the musical discourse, Beethoven treats the issue of dynamics with utmost care, permanently manifesting his disagreement regarding a poor performance that lacks expressiveness. "[...] all pianissimos and crescendos, all descrescendos and all fortes and fortissimos should have been deleted from my opera! In any case they are not observed. All desire to compose anything more ceases completely if I have to hear my work performed like that!'[4] Moreover, the strictness with which the composer would impose the dynamic performance of the musical text is also confirmed by his disciples. One of them, Ferdinand Reis remembers: "yet when I was at fault with regard to the expression, the crescendo or matters of that kind [...], he [Beethoven] would grow angry." [5]

With such undeniable proof, we cannot help wondering how it is possible that most of the existing errors are linked to the graphic representation of the sound intensity. The use of sonorities in a new and diversified manner, sometimes apparently impossible to achieve with the instruments of the time, has raised many suspicions regarding their authenticity. The wide palette of nuances, the subito piano following a crescendo, the sforzando at the end of a diminuendo or on the weak beat of the bar are in fact specific particularities of the Beethovenian style. Through their intensity, they manage to highlight the complexity of the musical discourse, an aspect of paramount importance for the interpretative conception. "All the pianissimos and the crescendos, all the descrescendos and all the fortissimos, deleted from the opus", as the composer would confess to Friedrich Sebastian Mayer, are typical of Beethoven's language, which bears the mark of originality.

The differences of dynamic nature appear in the piano and violin sonatas even from the first opus dedicated to this genre. In bar 21 of the first part of op. 12, no.1 in the first edition there is a particularity consisting in a dynamic offset between the two instruments, while other editions, such as Peters, reflect the uniformity of this aspect. As shown in figure 1 , there is a piano that the violin must perform while the piano has a fortepiano. Given that the previous bar creates tension in the melody by using the trill ornament, which the pianist must sustain for four beats, the fortepiano merely marks the release of this tension and shapes the dimensions of the new tonality. During this, the violin suddenly disappears, allowing the piano to highlight the recent tonic with both hands. The sudden entrance 
of the piano, following the forte nuance of the violin, is one of the dynamic features which is characteristic of Beethoven's style. The fugitive transition from one nuance to another, in the same context, in the Beetho-venian interpretation, is compared to a surprise meant to draw the audience's attention.

The differences continue with bars 37-38 from the variation I of the second part, where the violin's sforzando appears in the first edition printed on the last semiquaver, while in the other editions it appears together with the piano, on the penultimate semiquaver. Even though its synchronized interpretation is easier to be performed by the two instrumentalists and better fits the classical frames, let us not forget that it is exactly this sort of atypical situations that represent the Beethovenian style. We encounter a similar case in beat 60 , variation II, this time in the piano's score where, in the first edition, the sforzando appears on the third demisemiquaver note of the right hand rather than on the first, like the violin, as it is marked in the editions analyzed here.

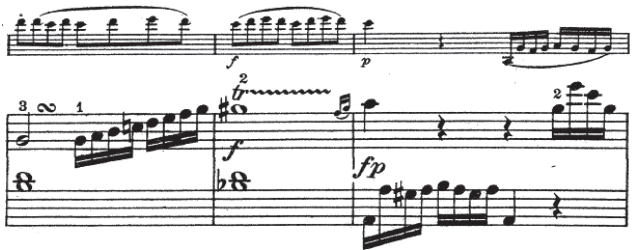

Figure 1. Beethoven's Sonata op.12, no.1, part I, bars 19, 20, 21

The third part of the Sonata op.12, no. 1 continues the list of inaccuracies with the absence, from the first publication, of bar 184, that of the violin's piano. This is a nuance whose presence is considered necessary in both instruments by other editions. Carefully analyzing this passage, we observe that the pianist only accompanies the violin's line which, having a main role in the fragment, leads the melody towards the tonic. It is clear that a nuance sustained by forte, as it appears in the first edition, on the background of a piano accompaniment, highlights even more the thematic motif characteristic to that respective passage.

Op. 30, no. 1 brings to the forefront a new issue of a dynamic nature; the sudden apparition of the piano after a roaring fortissimo nuance, as marked in the first edition, and not after a descrescendo, as suggested in other editions, which do nothing but erase the surprise effect Beethoven wished to create in bars 86 and 95 of the 4th part, variation IV.

In the fourth part of Sonata op.30 no. 2, the piano nuance in bars 43, 47, 205 and 209 is written erratically and imprecisely, even contradictorily, if we compare several editions (at the beginning of the bar / in the second half of the first beat / instrumentally synchronized or offset). The violinist and pedagogue Max Rostal consider that the piano interpretation beginning with the second quaver, as it is graphically presented in the Urtext edition, lends more meaning to the melody. "In all these cases I favour letting the piano in both instruments enter after, not at the beginning of the bar."[6] While accepting Max Rostal's suggestion with consideration, we believe that the inter-pretation of the piano nuance right on the first note of the first beat is more adequate. Above all, its approach at the beginning of the bar is in accordance with the graphic representation of the first edition (see figure 2). Analyzing it from a harmonic point of view, we cannot ignore the chaining of steps V-I which form an authentic cadence, closing at the end of the phrase. The tension specific to step $\mathrm{V}$, accumulated during the two bars preceding those in question, finds its resolution on the first step's piano, in the most natural of ways. We conclude our argumentation by mentioning that the sudden occurrence of a piano following a crescendo, even though it apparently coincides with a dynamic contradiction, is a stylistic particularity of the Beethovenian language.

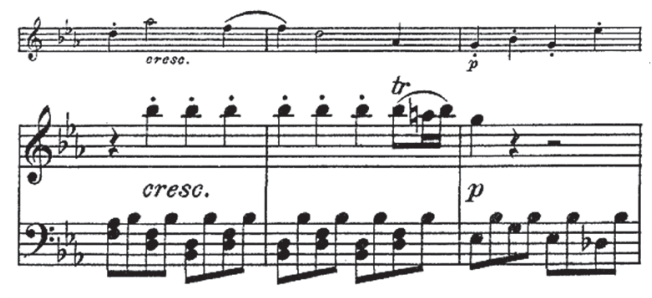

Figure 2. Beethoven's Sonata op.30, no.2, part IV, bars $45,46.47$ 
Like in op. 30, no. 2 the dynamic of Sonata op.30 no. 3 is extremely inaccurate both in the autograph and the first edition. Bars 7, 119 and 123 of part I present the entrance of the piano in piano, whilst the violin vibrates in forte. At the same time, the piano in one edition occurs at the beginning of the bar (Urtext), and in another on the second quaver (Peters), in the best of cases synchronized for both instruments. One plausible explanation for such negligence would be the large number of pieces on which Beethoven was working in parallel during that period. "I often compose three or four pieces at the same time"[7], the composer would confess, in one of the letters, to his friend Franz Wegeler. The great volume of work, compressed in a relatively short period of time, is responsible for the confusing content of the bars. From an interpretative viewpoint, Max Rostal proposes to the instrumentalists a debut in a general piano nuance, followed by a crescendo finalized in forte. Although all these indications are not present in any of the editions, he follows the principle of observing the crescendo in the third bar, which is identical in terms of the musical text to the other three. Although the rhythmic-melodic content is similar to the four aforementioned bars, the dynamic aspect of the musical content perceived at a phrase level must not be ignored. In the first edition, as well as the other publications, the nuance of the musical phrases that include bars 7, 119 and 123 starts in forte and not in the slightest degree in piano, as the segment of the third bar indicates. This detail changes the dynamic construction of the fragments, the piano being more suited in the context, by the dynamic contrast it creates. Thus, the idea of the violinist Max Rostal to homogenize the sound intensity of those respective bars by crescendo becomes implausible. The approach of the piano nuance throughout this bar is also confirmed by renowned performers of this sonata. Being well-known by their benchmark performance, the duo Martha Argerich - Gidon Kramer lend diversity to the musical discourse by rendering the dynamics perfectly according to their graphic representation in the existing publications. Also in part I of Sonata op. 30 no. 3, this time in bars
163-164, we observe in the first edition the occurrence of sforzandos not encountered in the bars corresponding to the 55, 56 exposition, as presented in figure 3, sforzandos which, as a matter of fact, are marked in both sections in the Peters and Urtext editions.

Taking the version of the first publication as a reference point, we consider this minor differentiation to be a means used by Beethoven to highlight the balance of the sonata form from a tonal point of view, conferring more personality to the reprise, which reduces and fixes the basic tonality.

In the grand Kreutzer op. 47, the dynamics of bars 45 and 366 of part I offer us different versions in the interpretation of the editions.

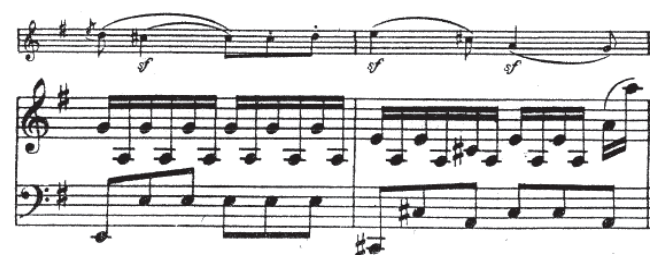

Figure 3. Beethoven's Sonata op.30, no.3, part I, bars 55,5

Peters marks piano in bar 45 on the first note, while in its correspondent in the reprise it is not earlier than the second quaver. Henle marks it at the beginning of each bar, except bar 366, where the violin begins on the second quaver and in the first edition on the second note, except in bar 45, where the piano starts in piano. According to the Schenkerian principle, any tonally anchored melodic line has a fundamental structure which seeks in the end to settle the accumulated tension on the first step. Hence, we consider the piano to be in accordance with this idea, given that it occurs at the beginning of the bar, on the third and the double base of the first step. Variation IV of the second part reveals a critical error. It is the descrescendo marked in bars 143 and 151 which follows a crescendo and precedes a piano. This indication does not appear in the original version, which makes us think about one of the Beethovenian traits responsible for the patenting of the procedure whereby a subito piano suddenly finishes with a crescendo. Therefore, the first edition's version, according to figure 4 , where the 
diminuendo does not exist, will remain emblematic in this case, reflecting an important stylistic aspect of Beethoven's language.

The adagio expressivo of the Sonata op.96 in the manuscript edition begins in piano. This indication is omitted in both the Peters and the Urtext editions. The dynamic detail is extremely important for the lyrical character that pervades through the entire sonata, the expressiveness of the second part suffering from the lack of the piano. In the same sonata, but this time in bar 61, the violin's subito piano on the last quaver is not reflected in the piano score. Still, Max Rostal proposes a dynamic synchronization of the instruments, for which he suggests a piano on the last quaver. "In my opinion, piano and violin should start the piano at the same time, on the last eighth-note."[8] It is our opinion that the lack of nuance in the piano score, forces it to continue its crescendo initiated two bars before, until close to the end of the part. This is unlikely, taking into account the fact that the following two bars provide a delicate instrumental dialogue, followed by a diminuendo, which closes the coda in a subtle pianissimo.

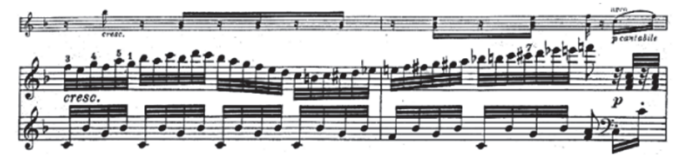

Figure 4. Beethoven's Sonata op.47, part II, bars 142,143

\subsection{Agogic Elements of Beethoven's Sonatas for Piano and Violin}

Indicating the speed of execution of an instrumental piece or fragment, agogics adds to the list of musical language elements by means of which a creation comes to life. The terminology "agogics" was introduced by Riemannin in 1884, in the work "Musikalische Dynamic und Agogic". Agogics is the musicological discipline which nuances tempos, characterizing them depending on the character and expressiveness of musical fragments. Starting with largissimo and arriving at prestissimo the tempos, due to the variable number of beats per minute, are often compared to the heart beat, the pulsation of which fluctuates depending on the inner feelings experienced by the instrumentalist. In a proper tempo, the interpreter can more easily absorb the character of the piece and, send the message that it expresses musically.

The Beethovenian agogic will always create controversies amongst cult music lovers, from novices to the most influential critics in the field. Opinions are split between the observance of the classical style, with rules imposing clarity, simplicity, balance and freedom of movement, sometimes with a rubato tendency, representative to the romanticism. Although historically placed within the classical period, Beethoven is the composer who broke away from this clean-cut current, changing its stylistic vision. Compared to the other two great Viennese classics, Mozart and Haydn, Beethoven, as Valentina Sandu-Dediu musicologist says, was the composer who, by sonorous and dramatic tensions, reflected the effect which the French Revolution had on society.[9] He understood the changes humanity went through at the beginning of the 19th century, the equality of rights and the freedom won by supreme sacrifice being the most highly priced values. As Adorno remarked "his work explodes the schema of a complaisant adequacy of music and society. In it, for all its idealism in tone and posture, the essence of society, for wich he speaks as the vicar of the total subject, becomes the essence of music itself." [10] By the plasticity of the musical fragments created, he reflects an intricate psychological substrate, externalized by the heroic breath of the pieces composed during his second period of creation, and the lyricism characterizing his last one.

The fullness of these intense inner states resides, alongside the dynamics, also in the agogic particularity of the phrases, handled with an unparalleled composer's virtuosity, as an interpreter. Czerny would remember, regarding the artistic representation of the master, that "only the main themes would be repeated in the same tempo, the rest of the phrases varying depending on their own significance" (Watson 2015, 15). In other words, the personalization of the agogic 
Beethovenian universe stubbornly refuses to align to a set of metronome-like rules, his personalization being for Beethoven more of a means to express his own "emotional chaos". This freedom of movement, which sometimes turns into a wild rubato, meant to ease the conveyance of certain inner feelings, is pertinently presented by Bernhard Bartels musicologist. "What we hear about [Beethoven] concerning metre, tempo and rhythm is very interesting. These truly artistic 'liberties' do occur to a great man. Whoever has to fight to get the metre should give up music. All rhythm, every tempo, all music is dictated from within."[11] Although the infirmity he suffered was almost total, the composer's agogic sense could easily compare to that of a perfectly healthy musician, the testimony of the violinist Josepth Bohm being an undeniable proof in this case. $\mathrm{He}$ remembers how, during a rehearsal, the composer, although in an advanced phase of deafness, had sensed the inadequate tempo fluctuations and insisted on the interpretation of the existing agogics exactly as its graphic representation. "The unhappy man [Beethoven] was so deaf that he could no longer hear the heavenly sound of his composition. And yet rehearsing in his presence was not easy. With close attention his eyes followed the bows and therefore he was able to judge the smallest fluctuations in tempo or rhythm and correct them at once." [12]

Carefully examining the editions under current analysis, we can notice that the graphic representation of the agogic terms was not, for the great composer, just as important a component as the dynamics. Apart from the last two sonatas, only sporadically do we encounter details regarding the means of agogic expression, despite their necessity in the interpretation and regardless of the existing testimonies about Beethoven's manner of execution. There are only three indications in the first eight sonatas: one rittardando in the first part, bar 242, of Sonata op.23, followed by an adagio in bars 32-33 of variation $\mathrm{V}$ from the Allegretto con Variazioni op. 30, no. 1 and a presto on the last 47 bars of the Allegro vivace of Sonata op.3 no. 3. Moreover, few details can be found regarding the general tempo of the pieces, this being for Beethoven more of an inexact movement, corresponding to a state connected to the inner perception and feelings of that respective moment.

The composer's preference for mentioning the speed of the piano and violin sonatas is not of a metronomic nature, the indication rather shaping the movement's character. Therefore, the beginning is marked by the effervescence of opus 12 , whose vitality is interpreted con brio and spirit. Beethoven's perspective thus reflects maturity towards the end of the last two works, which is treated with support and moderation. In line with the movement's character, Beethoven humorously approaches the Scherzos (scherzoso - joking) and the middle parts with the playable trait and expressiveness specific to the characteristic lyricism.

In the work "Beethoven, the Sonatas for Piano and Violin: Thoughts on their Interpretation", Max Rostal presents a few metronomic indications, with a view to avoiding erroneous or exaggerated approaches of the tempos. Crystallized as a result of his lifelong experience as a pedagogue and well-known interpreter, the suggestions establish the andantes between 50-60 bpm (beats per minute); within the same speed range, he proposes the performance of the adagio cantabile, following the acceleration up to $70 \mathrm{bpm}$ on that con expressione and finalizing with that sostenuto on $76 \mathrm{bpm}$; the allegro, the tempo dominating almost all speedy parts, appears to be defined between 104-160 bpm, starting from moderato and gradually moving forward to vivace, assai, molto and the presto, which increases the speed up to almost $190 \mathrm{bpm}$. With all these precious indications, one must not disregard the fact that a lengthy use of the metronome invariably leads to dry, forced and unnatural singing, which is the opposite to the composer's much-loved freedom of movement. Beethoven showed a total disagreement towards the rhythmical movement and rigidity of the metronome, the enemy of the expressive side, making history with his slogan "no more metronom".

\section{Conclusion}


It is a known fact that the success of any interpretation does not depend only on the numerous hours in the study room, but also to the added multiple specialised analyses. The first contact with the instrumental repertoire means its graphic analysis which, although it does not have the same weight as its technical and representative performance, must be treated with maximum responsibility and professionalism.

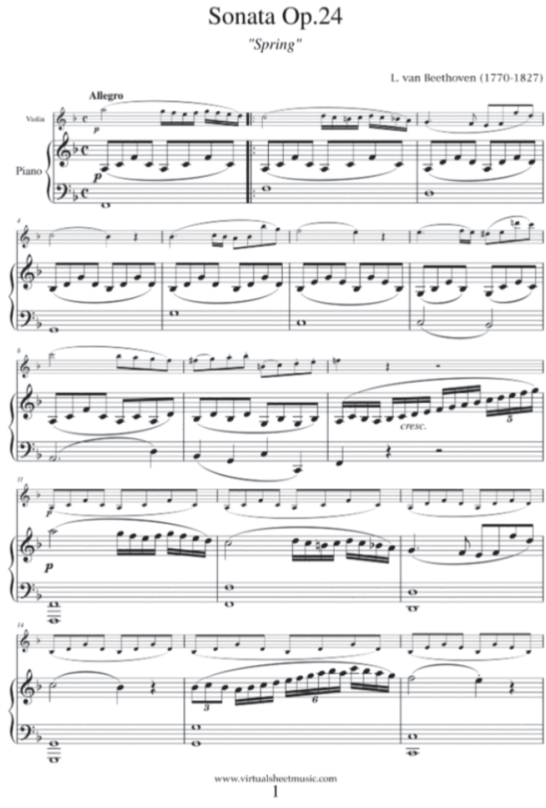

Consultation of the first edition or even of the manuscripts, their comparison to the edition under work, as well as the analysis of the omissions or alterations made by the editors, represents one of the paramount conditions of this analysis, which precedes the practical interpretation. A graphically complex approach is always favorable to the interpretative act, its value increasing together with the authentication of the stylistic and interpretative particularities. We should always bear in mind the certainty that the first edition is the source containing the most authentic elements, the only version on which the composer had the possibility to intervene when he thought it to be necessary. It should also represent a point of reference as a publication. The verification of the first edition, despite its format, which is difficult to read, due to the graphic representation specific to the 18th and 19th centuries, could shed some light on certain specific elements, through which the composer, in his act of creation, shaped the musical message. Always preoccupied with enriching and innovating the musical - instrumental language, especially from a dynamic viewpoint, Beethoven made his best to leave to future generations the most exact graphic representation of his grand vision. Deeply anchored, with his opus 12 , in the style of the second half of the 18th century, culminating with Kreutzer in a magnificent form, almost like a concert, and concluding with the lyrical atmosphere of opus 96, Beethoven generously offers us, with his ten piano and violin sonatas, the proof of a meticulous and authentic dynamic-agogic graphic representation.

\section{References}

M.Rostal, Beethoven The Sonatas for Piano and Violin, Toccata Press, London, 1985, p18. A.Watson, apud Beethoven's Chamber Music in Context, Boydell\&Brewer Press, Woodbridge, 2010, page 14.

L.Beethoven, Beethoven's Letters, Dover Publication, 1972, page 100.

A.Watson, Beethoven's Chamber Music in Context, Boydell\&Brewer Press, Woodbridge, 2010, page 15 .

M.Rostal, Beethoven The Sonatas for Piano and Violin,Toccata Press,London,1985, p116.

L.Beethoven, Beethoven's Letters, Dover Publication, 1972, page 18.

M.Rostal, Beethoven The Sonatas for Piano and Violin, Toccata Press, London,1985, p 177.

V.Sandu-Dediu, Ludwig van Beethoven, Didactic and Pedagogical Publishing, Bucharest, 2008, page 30.

T.W.Adorno, Beethoven The Philosophy of Music, Polity Press, Cambridge, 2005, p. 43. M.Rostal, Beethoven The Sonatas for Piano and Violin, Toccata Press, London, 1985, p 21 [11] L.Lockwood, Beethoven the Music and the Life, W.W.W.Norton \& Company, NewYork, 2003, p35. 